LETTERS

If you have a burning desire to respond to a paper published in Sex Transm Infect, why not make use of our "eletters" option?

Log on to the STI web site (Www. stijournal.com), find the paper that interests you, click on [Abstract] or [Full text] and send your electronic response by clicking on "eletters submit a response".

Providing your letter isn't libellous or obscene, it will be posted within seven days. You can view recent eletters by clicking on "Read eletters" on our homepage.

As before, the editors will decided whether to publish the eletter in a future print issue.

\section{Television coverage of AIDS and transmission of the AIDS virus}

The introduction of the government framework "The national strategy for sexual health and HIV"1 is necessary for attempts to prevent sexual causes of premature death and ill health, at a time when transmission of HIV is at a record level and heterosexual intercourse is the most commonly reported mode of transmission. However, policy formation alone will not be effective in the fight against AIDS in the United Kingdom. Commentators have noted television coverage of AIDS has declined as the progression of the AIDS epidemic has fallen from media interest. While television coverage raises AIDS awareness and encourages safer sex, it is unclear if it has an impact on infection rates. I have studied the association between television coverage and HIV transmission.

Television programmes with an AIDS specific content broadcast in the United Kingdom between 1981 and 2000 were identified. Criteria for inclusion were UK-wide terrestrial television programmes promoting AIDS awareness and encouraging the practice of safer sex; documenting the life of a person with AIDS; or a dramatisation featuring an AIDS storyline. Televised public education campaigns were excluded from the search, having been reported elsewhere. ${ }^{3}$ Television listings data were collected from a Scottish national newspaper (Daily Record) providing UK-wide television listings. Hand searching was conducted on the 1st, 15th, and 28th days of the months of February, May, August, and November; from 1981-2000: a 3.3\% sample of available coverage. The sample was augmented by additional sources. A search for programmes shown as part of a one-off media campaign (as reported in the literature); between 27 February and 6 March 1987 to promote AIDS awareness and encourage safer sex was conducted. Supplementary programmes were obtained ad hoc from reviewing The Guardian CD Rom (from 1989-2000) and The End of Innocence: Britain in the time of AIDS. ${ }^{4}$

Thirty seven UK terrestrial programmes covering HIV/AIDS were identified, the earliest in 1983, most recent in 2000, and a peak of programmes in the late 1980s. Between 1996 and 1999 no programmes covering HIV/AIDS were found. Twelve programmes about AIDS were shown during the media campaign of 1987. The decline in television coverage of AIDS contrasts with the steady increase in transmission of HIV (see fig $\mathrm{l}$ and table on STI website).

The findings of my study are tentative, but hint that television coverage of AIDS has declined as transmission of HIV continues. This complements Nicoll and colleagues argument that AIDS campaigns (often televised) are likely to have reduced HIV transmission in the 1980s. ${ }^{3}$ Television is a rich

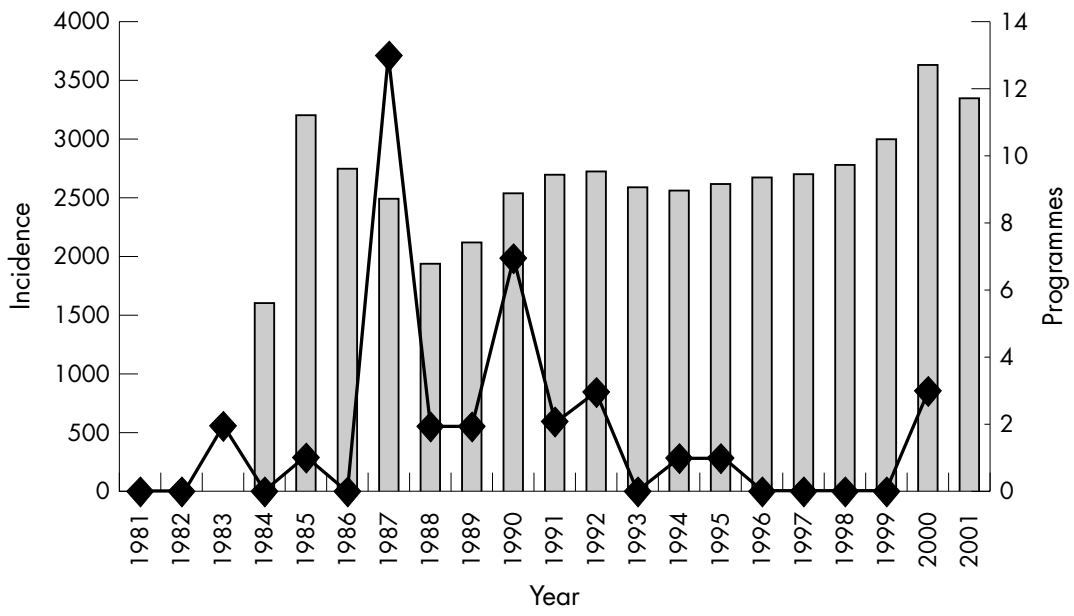

HIV incidence

Programmes

Figure 1 Television coverage of HIV/AIDS and incidence of HIV transmission in the UK, 1981-2001. source of information about AIDS, offering a powerful while unevaluated medium for promoting AIDS awareness and safer sex to the general public. Given the current low level of media interest and the ceaseless increase of HIV transmission, it may be beneficial to formally evaluate a national media campaign on this important public health issue using quasi-experimental methods.

D J Nicolson

Centre for Health Services Research, School of Health Sciences, University of Newcastle, 21 Claremont Place,

Newcastle upon Tyne NE2 4AA, UK

Correspondence to: d.j.nicolson@ncl.ac.uk

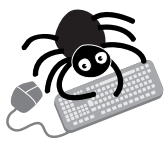

A table of television coverage of AIDS 1981-2000 is on the STI website www.stijournal.com/ supplemental

\section{References}

1 Department of Health. The national strategy for sexual health and HIV. London: $\mathrm{DOH}$ 2001. www.doh.gov.uk/nshs/index.htm

2 Jackson T. No news is bad news. BM 2000;321:1419.

3 Nicoll A, Hughes $G$, Donnelly $M$, et al. Assessing the impact of national anti-HIV sexual health campaigns: trends in the transmission of HIV and other sexually transmitted infections in England. Sex Transm Infect 2001;77:242-7.

4 Garfield S. The end of innocence: Britain in the time of AIDS. London: Faber and Faber, 1995

Accepted for publication 17 October 2002

High frequency of antibodies to syphilis and HIV in hepatitis C virus positive blood donors may reflect its sexual transmission in this region

Hepatitis C virus (HCV) infection is a great cause of concern because of the risk of chronicity and other sequelae. Studies on the prevalence behaviour pattern and sexual transmission of HCV infection among the population are required for formulating strategies to control spread of HCV. ${ }^{1}$ The aim of this study was to evaluate the occurrence of HCV in voluntary blood donors as they are known to be a high risk population ${ }^{23}$ for transmission of these infectious agents. Comparison was made between the presence of syphilis, HBV, and HIV infection in HCV negative and positive blood donors to confirm these as markers or predictors of HIV infection in a high risk population which may reflect the transmission of HCV by a sexual route.

Voluntary blood donors $(\mathrm{n}=3905)$ from New Delhi, India, were randomly recruited between August 2001 to March 2002 and were unpaid. These donors were screened for antibodies to VDRL, hepatitis B surface antigen (HBsAg), hepatitis C virus (HCV), and HIV using previously validated second generation ELISA kits. Data were analysed using the $\chi^{2}$ test. Odds ratio (OR) was used to measure strength of an association. 
Table 1 Percentage positivity of HBsAg, VDRL, and HIV in HCV positive and negative blood donors

\begin{tabular}{llll}
\hline & HCV + ve $(n=61)$ & HCV - ve $(n=3844)$ & Total \\
\hline HBsAg $(\%)$ & $3(4.91)$ & $106(2.75)$ & $109(\mathrm{OR}=1.82)$ \\
VDRL $(\%)$ & $3(4.91)$ & $129(3.35)$ & $132(\mathrm{OR}=1.48)$ \\
HIV $(\%)$ & $9(14.75)$ & $31(0.80)$ & $40(\mathrm{OR}=21.2)$ \\
\hline
\end{tabular}

$\chi^{2}=122.8 ; p<0.001$

$\mathrm{OR}=$ odds ratio, $\mathrm{HCV}$ positive versus $\mathrm{HCV}$ negative negative blood donors.

The antibodies to HCV were detected in 61 (1.56\%), HBsAg in $109(2.79 \%)$, VDRL in 132 $(3.38 \%)$, and HIV in $40(1.02 \%)$ donors. In HCV negative blood donors, VDRL was detected in $129(3.35 \%)$, HBsAg in $106(2.75 \%)$ and HIV in $31(0.8 \%)$ donors, while in HCV positive blood donors HIV positivity increased significantly to nine ( $14.75 \%)$ OR (21.2) and VDRL and HBsAg reactivity increased to three $(4.91 \%)$ (OR 1.82 and 1.48 respectively). Thus HIV, VDRL, and HBsAg reactivity was found $21.2,1.48$, and 1.82 times more often respectively in HCV positive blood donors (table 1).

In conclusion, the high frequency of antibodies to syphilis and HIV in HCV positive blood donors may confirm this as a marker or predictor of HIV infection in a high risk popuation and may also reflect the risk of ransmission of HCV by the sexual route, which seems to vary with the population studied.

A Mittal

Institute of Pathology (ICMR), Post Box No 4909 Safdariung Hospital Campus, New Delhi -1 10029, India; amittal_iop@yahoo.com

\section{References}

1 World Health Organization. Global surveillance and control of hepatitis C. J Viral Hep 1999:6:35-47.

2 Smikle M, Dowe G, Kong-HT, et al. Hepatitis $B$ and $C$ viruses and sexually transmitted disease patients in Jamaica. Sex Transm Infect 2001;77:295-6.

3 King SD, Dodd RY, Haynes $G$, et al Prevalence of antibodies to hepatitis $C$ virus and other markers in Jamaica. West Ind Med J 1995;44:55-7.

Accepted for publication 30 October 2002

\section{Self obtained samples for genitourinary infections}

We assessed the concept of self sampling, as part of screening for sexually transmitted diseases, first in the early 1990s in a pilot study. The aim was to assess the validity and acceptability of the procedure as an alternative for the sex industry workers (or as a supplementary method between attendances), for those who are reluctant or unable to attend GUM clinics frequently. Microbiological techniques then were not as developed or as sensitive as today's (PCR) tests. ${ }^{2}$ Since then, other studies reported on the feasibility and acceptability of self obtained samples. ${ }^{3}$

We read with interest, the article published in $S T I^{5}$ regarding the diagnosis of chlamydia, gonorrhoea and trichomonas infections by self obtained low vaginal swabs. The techniques employed in the Australian study (patients obtaining swabs while sitting or standing) would allow less access to the genital tract than our originally proposed squatting positions. In our study, the patient was advised first by a female nurse on the squatting position and locating the cervix She was readvised on repeating the procedure and the attempt to take the swabs from the cervical surface. In our study, $86.7 \%$ of patients reported their ability to access the cervix (and, therefore, obtain high vaginal/ cervical samples). The squatting position has the advantage of providing patients with the freedom to use both hands (one of which may be used to open the vulval lips). The technique is similar to that employed by women for self examination before the insertion of a cervical cap or for the presence of the intrauterine contraceptive device threads.

The new methods of information technology, with their declining cost, can provide extra support to the concept of self obtained samples with easier patient access to their results. The result of the tests may then be obtained by the patient by telephone (possibly via an automated service or a text message, using an identification code number). The procedure is already in use by the banking services for accessing personal and confidential information. It is possible to provide the sampling materials in a "test pack" that may be returned to a central laboratory, by post The pack may include information and explanatory notes and a coded identification number. This would help to identify the patient's samples, with confidentiality.

The recent escalation in the incidence of sexually transmitted infections, coupled with the increasing workload for GUM clinics is representing a challenge for adopting new ways in combatting the spread of sexually transmitted infections. The exploitation of new ideas, methods, and technologies could be of benefit, especially in areas out of access to advanced laboratory investigations (remote and rural areas). It could also be used as a supplementary method to current medical care (between visits) in special patient groups (for example, adolescents ${ }^{3}$ and sex industry workers ${ }^{6}$ ).

$$
\begin{array}{r}
\text { A R Markos } \\
\text { Staffordshire General Hospital, Weston Road, } \\
\text { Stafford ST16 3SA, UK; } \\
\text { stephanie.thorpe@msgh-tr.wmids.nhs.uk }
\end{array}
$$

\section{References}

1 Markos AR, Wade AA, Walzman M, et al. Self sampling as part of screening for sexually transmitted diseases in clinic attenders. A preliminary study. Int J STD AIDS 1994:5:284-6.

2 Gaydos CA, Rompalo AM. The use of urine and self-obtained vaginal swabs for the diagnosis of sexually transmitted diseases. Curr Infect Dis Rep 2002;4: 148-57.

3 Wiesenfeld HC, Lowry DL, Heine RP, et al. Self-collection of vaginal swabs for the detection of chlamydia, gonorrhoea, and trichomoniasis: opportunity to encourage sexually transmitted disease testing among adolescents. Sex Transm Dis 2001 ; 28:321-5.

4 Serlin M, Shafer MA, Tebb K, et al. What sexually transmitted disease screening method does the adolescent prefer? Adolescents' attitudes toward first-void urine, self-collected vaginal swab, and pelvic examination. Arch Pediatr Adolesc Med 2002;156:588-91.
5 Garrow SC, Smith DW, Harnett GB. The diagnosis of chlamydia, gonorrhoea, and trichomonas infections by self obtained low vaginal swabs, in remote northern Australian clinical practice. Sex Transm Infect 2002;78:278-81.

6 Morton AN, Wakefield T, Tabrizi SN, et al. An outreach programme for sexually transmitted infection screening in street sex workers using self-administered samples. Int J STD AIDS 1999;10:741-3.

Accepted for publication 30 October 2002

\section{A survey of STI policies and programmes in Europe}

The survey by Dehne et al was carried out in 1998-9 and inevitably does not necessarily represent the current situation. ${ }^{1}$ The authors report that the United Kingdom has no national STI programme and management guidelines. The first ever national strategy for sexual health and HIV for England was published in 2001. ${ }^{2}$ It contains the two key objectives of ensuring that everyone has better access to information on sexual health and to make services more available and accessible to all those who require them at all ages. The strategy also has specific aims of reducing acquisition, transmission and the prevalence of undiagnosed HIV and STIs. Specific targets to increase the uptake of HIV testing in hepatitis $\mathrm{B}$ vaccination have also been set.

The issue of case management guidelines was not detailed in the strategy since this has been specifically tackled by the specialty of genitourinary medicine. A clinical effectiveness group was set up between the Association of Genitourinary Medicine and the Medical Society for the Study of Venereal Diseases in 1997, with the specific remit of producing evidence based national guidelines and standards for those working in the specialty of genitourinary medicine. These were published in STI in $1999^{3}$ and updated in $2002{ }^{4}$

I hope these observations will help to update the survey with particular reference to England.

M W Adler

Department of Sexually Transmitted Diseases, Royal Free and University College Medical School, The Mortimer Market Centre, Off Capper Street, London WC1E 6AU, UK; madler@gum.ucl.ac.uk

\section{References}

1 Dehne KL, Rieder G, Neckermann C, et al. A survey of STI policies and programmes in Europe; preliminary results. Sex Transm Infect 2002;78:380-4.

2 Department of Health. The national strategy for sexual health and HIV. London: DoH 2001. www.doh.gov.uk/nshs/index.htm

3 Radcliffe K, Ahmed-Jushuf I, Cowan F, et al. 1999 UK national guidelines on sexually transmitted infections and closely related conditions. Sex Transm Infect 1999;75(suppl 1). www.agum.org.uk

4 FitzGerald R, Ahmed-Jushuf I, Radcliffe KW et al. Revised UK national guidelines on sexually transmitted infections and closely related conditions 2002. Sex Transm Infect 2002;78:81-2.

Accepted for publication 29 November 2002

Polymorphic immune restoration syndrome after effective HAART

HAART is able to suppress HIV replication and restore specific immune responses. We and others $^{12}$ have demonstrated that previously 


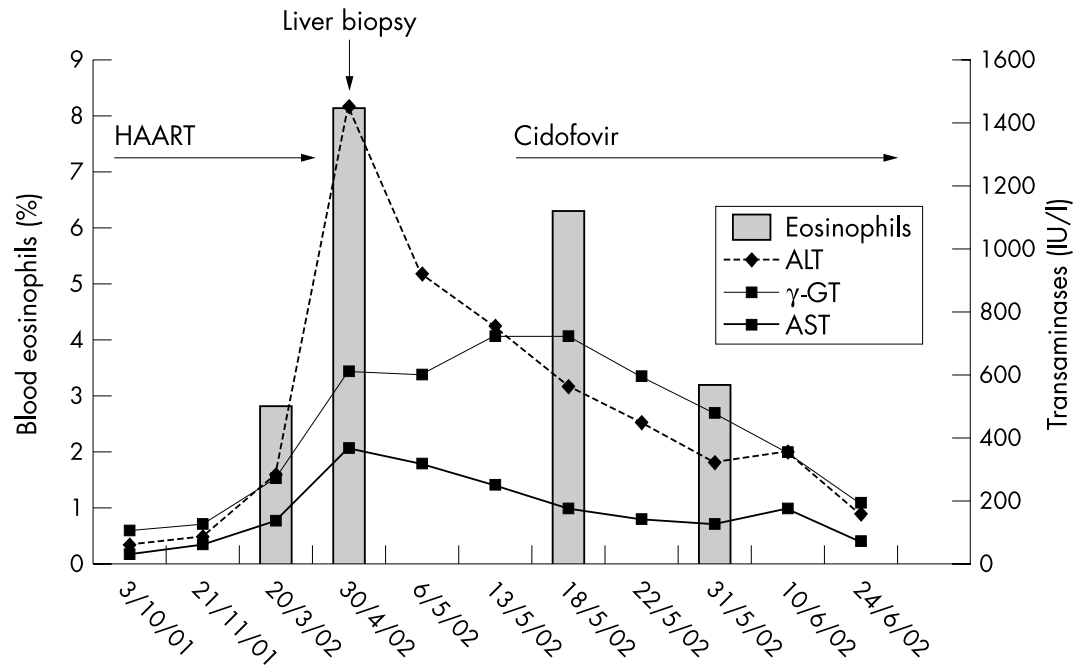

Figure 1 Haematochemical clinical course of the study patient.

untreatable progressive multifocal leucoencephalopathy (PML) may improve and has very rarely been reported following HAART. However, CD4+ increase is also associated with inflammatory reactions to previously silent infectious agents, as well as aberrant immune phenomena.

\section{Case report}

A 27 year old $\mathrm{HIV} / \mathrm{HCV}$ (hepatitis C virus) patient was observed in 1997 with a CD4+ count of 357 cells $\times 10^{6} / 1$ and HIV-RNA $>1000000$ copies/ml. HAART was started and maintained until 1999 when it was stopped at the patient's request. On October 2001 he returned asymptomatic, with a CD4+ cell count of $34 \times 10^{6} / 1$ and HIV-RNA 130000 copies/ml. Stavudine + lamivudine + nevirapine were then started, together with trimethoprim-sulfamethoxazole. He experienced an optimal response (CD4+ count 159 $\times 10^{6} / \mathrm{l}$, HIV-RNA $<50$ copies $/ \mathrm{ml}$ on March 2002). One month later, the patient was admitted because of mental slowness, aphasia, ataxia, impairment of fine movements of the right arm, and hypostenia of the right leg. He was afebrile and laboratory tests showed WBC $5300 \times 10^{6} / 1$, RBC $4550 \times 10^{6} / \mathrm{l}, \mathrm{Hb} 16.1$ g/dl, PLT: $259 \times 10^{9} /$, eosinophils $8.3 \%$, AST 369 IU/l, ALT 1446 IU/l, $\gamma$-GT 599 IU/l, PT 84\%, and raised total plasma IgE $330 \mathrm{IU} / \mathrm{ml}$. Toxoplasma serology, HBsAg, HBsAb, and HAV-IgM were negative; HBc-IgG and HAVIgG were positive; and HCV-RNA was $172 \times$ $10^{6}$ copies $/ \mathrm{ml}$ (baseline $13 \times 10^{6} / \mathrm{l}$ copies as at October 2001, before HAART). HAART was stopped and liver biopsy performed, showing chronic hepatitis with cholestasis, marked eosinophilia, parenchymal and periportal infiltrates of predominant lymphocytes, and plasma cells suggestive of allergic disease. Cranial magnetic resonance imaging scans revealed subcortical white matter lesions in both frontal lobes and internal capsule with faint peripheral enhancement after gadolinium contrast. Cerebrospinal fluid analysis was normal, fungal and bacterial cultures, cryptococcal antigen, and polymerase chain reaction for HSV-1/2, varicella zoster virus, EpsteinBarr virus, cytomegalovirus, Mycobacterium spp were negative, while JCV-DNA was positive; a cidofovir standard dose was initiated. Subsequently, progressive improvement was observed (fig l) and PML stabilised.

\section{Comment}

We report a complex polymorphic immune restoration syndrome of PML (demonstrated also by JCV-PCR in contrast with previous reports ${ }^{2}$ ) combined with the first case of liver damage related to delayed immune mediated hypersensitivity reaction to nevirapine.

Several facts support an immunopathogenetic role of aberrant immune recovery in this case: (i) these phenomena occurred together in concomitance with raising CD4+ T cell count under effective HAART; (ii) PML during HAART is exceptional; (iii) both PML during HAART $^{2}$ and nevirapine hypersensitivity ${ }^{4}$ occurred during the first weeks of therapy in the case series reported so far; (iv) nevirapine hypersensitivity is frequent in conditions of preserved immune response. ${ }^{6}$ This underlines that pathogenic mechanisms and immunological factors associated with immune restoration diseases may be diverse and unexpected. Moreover, nevirapine hypersensitivity is immediate while this case of liver damage occurred after a substantial period on nevirapine and with concomitant elevation of $\gamma$-GT enzyme and increase in HCV replication. Therefore, it would have been very difficult to make the correct differential diagnosis with either late onset metabolic idiosyncrasy to nevirapine or relapsing HCV hepatitis without liver histology. Thus, avoiding liver biopsy in such cases may lead to an underestimation of the causative role of nevirapine.

E Quiros-Roldan, C Torti, S Casari, F Moretti, M Puoti, G Carosi Institute of Infectious and Tropical Diseases, University of Brescia, Brescia, Italy

L Bercich

First Service of Pathological Anatomy, Spedali Civili General Hospital, Brescia, Italy

Correspondence to: Eugenia Quiros-Roldan, MD, $\mathrm{PhD}$, Institute of Infectious and Tropical Diseases, P le Spedali Civili, 1, 25123 Brescia, Italy, carlotorti@hotmail.com

\section{References}

1 Cinque P, Casari S, Bertelli D. Progressive multifocal leukoencephalopathy, HIV, and highly active antiretroviral therapy. N Engl J Med 1998;339:848-9.

2 Mayo J, Collazos J, Martinez E. Progressive multifocal leukoencephalopathy following initiation of highly active antiretroviral therapy. AIDS 1998;12:1720-2.
3 French MA Lenzo $N$, Jonh $M$, et al. Immune restoration disease after the treatment of immunodeficient HIV-infected patients with highly active antiretroviral therapy. HIV Med 2000;1:107-15.

4 Carr A, Cooper DA. Adverse effects of antiretroviral therapy. Lance 2000;356: 1423-30

5 Mackie N, Sabin CA, Weston R, et al. Durability and tolerability of nevirapine containing regimens in a cohort of antiretroviral-naive HIV-positive patients (Abstract). HIV Med 2002;3:P8.

6 CDC. Serious adverse events attributed to nevirapine regimens for postexposure prophylaxis after HIV exposures-worldwide, 1997-2000. MMWR Morb Mortal Wkly Rep 2001;49:1153-3.

Accepted for publication 29 November 2002

\section{NOTICES}

\section{International Herpes Alliance and International Herpes Management Forum}

The International Herpes Alliance has introduced a web site (www.herpesalliance.org) where patient information leaflets can be downloaded. Its sister organisation the International Herpes Management Forum (web site: www.IHMF.org) has launched new guidelines on the management of herpesvirus infections in pregnancy at the 9th International Congress on Infectious Disease (ICID) in Buenos Aires.

\section{Pan-American Health Organization, regional office of the World Health Organization}

A catalogue of publications is available online (www.paho.org). The monthly journal of PAHO, the Pan American Journal of Public Health, is also available (subscriptions: pubsvc@tsp.sheridan.com).

\section{International Congress of the Society of The Fetus as a Patient}

1-4 May 2003, Gran Hotel Sitges, BarcelonaSitges, Spain.

Further details: (fax: + 3493418 7832; email: bcn2003@iudexeus.uab.es).

\section{Australasian Sexual Health Conference: Tango down South-2003!}

4-7 June 2003, Christchurch Convention Centre, New Zealand.

Further details: Dart Associates (tel: +02 9418 9396/97; email: dartconv@mpx.com.au web site: http://www.acshp.org.au).

\section{NSC Dermatology Update 2003}

27-29 June 2003, Singapore.

Further details: Mrs Alice Chew, National Skin Centre, I Mandalay Road, Singapore 308205 (tel: +65 6350 8405; fax: +65 6253 3225; email: training@nsc.gov.sg). 